\title{
Factors associated with adverse pregnancy outcomes among women who delivered at intermediate hospital oshakati, Namibia
}

\author{
Teopolina N.Mungoba ${ }^{1}$, Honore Kabwebwe Mitonga ${ }^{2 *}$, Sabina Aishe David ${ }^{3}$, Alfred Musekiwa ${ }^{4}$, Tuyakule Nakale ${ }^{5}$ \\ ${ }^{1}$ Ministry of Health and Social Services, Management Information System Division, Keetmanshoop, Namibia \\ ${ }^{2}$ School of Public Health, Faculty of Health Sciences, University of Namibia, Oshakati, Namibia \\ ${ }^{3}$ School of Nursing, Faculty of Health Sciences, University of Namibia, Oshakati, Namibia \\ 4 Division of Global Health Protection, U.S. Centers for Disease Control and Prevention, Pretoria, South Africa \\ 5 Namibia Institute of Pathology, Microbiology Division, Windhoek, Namibia \\ *Corresponding author E-mail: honoremitonga@gmail.com
}

\begin{abstract}
Background: Globally, the leading cause of death among females aged 15-49 years old is maternal mortality. More than 1,500 women die each day from pregnancy related causes resulting in an estimated 550,000 maternal deaths annually. We identified risk factors associated with adverse pregnancy outcomes.

Methods: We conducted a descriptive, cross-sectional study, in which we administered a structured questionnaire through face to face interviews. We also applied the multivariate logistic regression model to determine factors associated with adverse pregnancy outcomes. Results: We enrolled a total of 306 pregnant women of whom $50 \%(\mathrm{n}=153)$ were $12-19$ years old and $50 \%(\mathrm{n}=153)$ were $20-45$ years old. Maternal death occurred only in the $20-45$ years old mothers $(6 / 153,3.9 \%)$. In multivariate analysis, living in a rural area (aOR2.00, 95\% CI: 1.08 to 3.69, p=0.027), shorter gestational period [32-37 weeks] (aOR4.84, 95\% CI: 2.31 to 10.14, p=0.0007), haemoglobin level <10gm\% (aOR3.87, 95\%CI: 1.79 to $8.39, \mathrm{p}=0.001$ ), obesity [BMI $\geq 30 \mathrm{~kg} / \mathrm{m}^{2}$ ] (aOR4.89, 95\% CI: 1.38 to $\left.17.37, \mathrm{p}=0.014\right)$ and moderately high blood pressure [SBP/DBP of 150/100-159/109] (aOR15.15, 95\% CI: 1.78 to 128.68, p=0.013) were significantly associated with adverse pregnancy outcomes.

Conclusion: In this study, we identified living in a rural area, shorter gestational period, haemoglobin level $<10$ gm $\%$, obesity, and having moderately high blood pressure to be risk factors for adverse pregnancy outcomes. All the maternal deaths were in the 20-45 years old pregnant mothers. We recommend educating women on these risk factors in order to reduce the burden of adverse pregnancy outcomes.
\end{abstract}

Keywords: Adverse Pregnancy Outcomes; Intermediate Hospital Oshakati; Angola; Namibia.

\section{Introduction}

Globally, the leading cause of death among females aged 15-49 years old is maternal mortality. More than 1,500 women die each day from pregnancy related causes resulting in an estimated 550,000 maternal deaths annually (U.N.General Assembly, 2009). In 2010, the WHO, UNICEF, UNFPA and the World Bank estimated that about 260 women die per 100000 live births worldwide, and most of these deaths occur in developing countries particularly in the Sub-Saharan Africa. These estimates indicate that Africa recorded the highest Maternal Mortality Ratio (MMR) of 620 per 100,000 live births, whilst Europe recorded the lowest maternal mortality rate of 16 per 100,000 live births (WHO, 2012). Namibia recorded 113 maternal deaths from $1^{\text {st }}$ January 2008 to $31^{\text {st }}$ May 2010 (MoHSS, 2011). In order to reduce maternal mortality (MM), the Sustainable Development Goal (SDG 3) of ensuring healthy lives and promoting well-being for all has been proposed (UNICEF, 2008).

Maternal mortality is one of many adverse pregnancy outcomes. The other adverse pregnancy outcomes (APOs) include preterm birth, neonatal and perinatal death, postpartum haemorrhage, puerperal sepsis, pre-eclampsia or eclampsia, caesarean section, low birthweight, foetal death/stillbirth (Winthrop-University Hospital,
2015). Neonatal mortality in a neighbouring country, Botswana, was estimated at 46 per 1,000 live births in 2004 (UNICEF, 2008). More recent studies conducted at community-level in Burkina Faso have reported perinatal mortality of 32 per 1000 in Houndé (Roberfroid, et al.2008), A study conducted in Nigeria reported that puerperal sepsis is a second leading cause of death accounting for $26.3 \%$ of maternal deaths (WHO, 2010).

The burden of adverse pregnancy outcomes is high in Namibia. Out of a total of 10, 446 births recorded in Intermediate Hospital Oshakati, Oshana region, Namibia, in 2011 to 2013, there were 34 maternal deaths $(0.3 \%), 369$ neonatal deaths $(3.5 \%), 403$ perinatal deaths $(3.9 \%), 879$ premature births $(8.4 \%), 2,448$ caesarean sections (23.4\%) (Intermediate Hospital Oshakati Report, 2011 to 2013). In 2013 alone, Oshana region recorded the highest number of maternal deaths, although it ranked sixth in the number of births in that year (MoHSS, 2014). In this study, we identified risk factors for APOs in a high maternal mortality Oshana region, Namibia, in order to inform strategies for reducing the burden of APOs in Namibia.

\section{Methods}

\subsection{Study design}


We conducted a quantitative, descriptive, cross-sectional study from July - September 2015.

\subsection{Setting}

We conducted this study at Intermediate Hospital Oshakati (IHO) maternity ward, Oshana region, Namibia. IHO is one of the northern regional hospitals with a bed capacity of 768 . The maternity ward has a bed capacity of 78 with an average of 100 babies delivered per week. It consists of 8 obstetric and 4 medical doctors, 37 registered and 15 enrolled midwife nurses. This hospital had the highest maternal deaths and child mortality in the region.

\subsection{Participants}

We included all pregnant women giving birth at Intermediate Hospital Oshakati during the period of study of four months.

\subsection{Variable and measurements}

We designed a pre-tested structured questionnaire for capturing all the variables. Section A included demographic characteristics of the pregnant mother: age, region, educational level, employment status, marital status, and residential area. Section B addressed potential risk factors: gravidity (number of pregnancy occurred), gestation (weeks of pregnancy), parity (number of children born alive), HIV status, body mass index (BMI), haemoglobin, and blood pressure (BP). Section C focused on patient outcomes: maternal death, perinatal death, neonatal death, postpartum haemorrhage, caesarean section, puerperal sepsis, eclampsia, low birth weight $(<2500 \mathrm{~g})$, and others.

The HIV status was extracted from the pregnant mother's health record. The BMI of the mothers was taken using an electronic UNICEF Secca scale. The weight of the mothers was taken using a scale. The heights of the mothers were measured (in metres) while standing with their feet flat on the base of a special Lshaped, metal height measure. Heels, buttocks and backs were made to touch the backboard and the head was positioned so that the mother was looking directly forward. The BMI ranged as underweight $\left(<18.5 \mathrm{~kg} / \mathrm{m}^{2}\right)$, normal weight $\left(18.5-24.9 \mathrm{~kg} / \mathrm{m}^{2}\right)$, overweight $\left(25-29.9 \mathrm{~kg} / \mathrm{m}^{2}\right)$ and obesity $\left(>30 \mathrm{~kg} / \mathrm{m}^{2}\right)$. The electronic blood pressure (BP) apparatus was used to measure $\mathrm{BP}$ of the mothers, which ranged as normal $(<140 / 90 \mathrm{mmHg})$, mildly high $(140 / 90$ - 149/99mmHg), moderate high (150/100 $159 / 109 \mathrm{mmHg}$ ) and severely high $(>160 / 110 \mathrm{mmHg})$. The level of haemoglobin was taken using the electronic haemoglobin machine and was categorized as either $<10 \mathrm{gm} \%$ or $>10 \mathrm{gm} \%$.

\subsection{Data collection}

We administered the questionnaire to each pregnant mother who delivered at Intermediate Hospital Oshakati during the study period. We conducted face to face interviews after making arrangements with the regional director, the hospital medical superintendent, the hospital nurse manager and supervisor for the maternity ward.

\subsection{Bias}

We conducted a pilot test prior to the actual data collection on pregnant mothers with similar characteristics to the sample and any unclear items were corrected. We assessed relevance and accuracy of the questionnaire in terms of information retrieval and relevance. We applied the multivariable logistic regression model in the analysis to account for any potential confounding bias.

\subsection{Sample size}

The sample size was 306 women delivering at Intermediate Hospital Oshakati during the study period.

\subsection{Statistical methods}

We used descriptive statistics to summarize the data which were presented as frequency distribution tables consisting of frequencies and percentages. We applied the multivariate logistic regression model to determine factors associated with adverse pregnancy outcomes and reported Odds Ratios (OR), 95\% confidence intervals and $p$-values to demonstrate statistical significance. The dependent variable was any adverse pregnancy outcomes (maternal mortality, perinatal death, neonatal death, postpartum haemorrhage, puerperal sepsis, caesarean section or low birth weight) and the independent variables were the potential risk factors (sex, region, educational level, residential area, age, gravidity, gestation, parity, HIV status, BMI and hemoglobin).

We performed bivariate analysis first and entered all variables with p-values less than 0.2 in the multivariate analysis model. We used the manual forward stepwise procedure and used a cut off $\mathrm{p}$ value of less than 0.05 for statistical significance. We ensured that only non-collinear variables were entered into the multivariate model by performing multicollinearity tests prior to adding variables into the model. We also applied the Hosmer-Lemeshow Chisquare goodness of fit test to assess the multivariate model. We captured data using Epi-Info version 7 (CDC, 2010) and used STATA version 12 in all statistical analyses.

\subsection{Ethical issues}

We obtained permission to conduct this study from the University of Namibia Postgraduate Studies Committee, the Namibia Ministry of Health and Social Services, and the Oshana Regional Director. We also obtained written informed consent from the study participants (mothers). We removed the participants identifying details (names and surnames) from the data set we used in the analysis.

\section{Results}

\subsection{Demographic characteristics}

We enrolled a total of 306 mothers who gave birth at the Intermediate Hospital Oshakati (IHO) during the study period. The mean $( \pm$ SD) age of pregnant women participating in the study was 23 $( \pm 7.02)$ years and ranged from 12 years to 45 years. More than half of the cases were coming from Oshana region 162 (52.9\%), followed by Omusati region $59(19.3 \%)$, and the least majority were from Kunene region $6(3.6 \%)$. Almost $90 \%$ of the participants $267(87.3 \%)$ were unemployed, while 39 (12.7\%) were employed. More than ninety percent $286(93.5 \%)$ were single, while $20(6.5 \%)$ were married. About three quarters of the participants $232(75.8 \%)$ were from rural areas, while 74 (24.2\%) were residing in urban areas. Almost three quarters of participants had attended up to secondary school 228 (74.5\%), followed by primary education $45(14,7 \%)$, while the least of participants attended tertiary education $11(3.6 \%)$ (Table 1$)$.

\subsection{Adverse pregnancy outcomes}

Out of the 306 mothers enrolled in the study, a total of 164 $(53.59 \%)$ experienced an adverse pregnancy outcome (maternal death, neonatal death, perinatal death, postpartum haemorrhage, puerperal sepsis, eclampsia, caesarean section, or low birthweight). We found six maternal deaths [all in mothers aged 20-45 years] $(1.96 \%)$, four neonatal deaths $(1.31 \%)$, nine $(2.94 \%)$ perinatal deaths (five fresh still births and four macerated deaths), 20 postpartum haemorrhages $(6.54 \%)$, one puerperal sepsis $(0.33 \%)$, 28 eclampsia $(9.15 \%), 100$ caesarean sections $(32.68 \%)$, and 66 low birth weight babies (21.57\%) (Table 3). 
Table 1: Socio-Demographic Characteristics of Women who delivered at Intermediate Hospital Oshakati, Namibia, July - September 2015

\begin{tabular}{|c|c|c|}
\hline Characteristics & Frequency & Percentage $\%$ \\
\hline \multicolumn{3}{|l|}{ Age: } \\
\hline $12-15$ & 11 & 3.5 \\
\hline $16-19$ & 142 & 46.4 \\
\hline $20-23$ & 41 & 13.4 \\
\hline $24-27$ & 31 & 10.1 \\
\hline $28-31$ & 29 & 9.4 \\
\hline $32-35$ & 25 & 8.1 \\
\hline $36-45$ & 27 & 8.8 \\
\hline \multicolumn{3}{|l|}{ Region: } \\
\hline Kunene & 7 & 2.2 \\
\hline Non -Namibian (Angolan) & 22 & 7.1 \\
\hline Ohangwena & 47 & 15.3 \\
\hline Omusati & 61 & 19.9 \\
\hline Oshana & 158 & 51.6 \\
\hline Oshikoto & 11 & 3.5 \\
\hline \multicolumn{3}{|l|}{ Employment: } \\
\hline Employed & 39 & 13 \\
\hline Unemployed & 267 & 87 \\
\hline \multicolumn{3}{|l|}{ Marital Status: } \\
\hline Married & 20 & 7 \\
\hline Single & 286 & 93 \\
\hline \multicolumn{3}{|l|}{ Residential area: } \\
\hline Urban & 232 & 76 \\
\hline Rural & 74 & 24 \\
\hline \multicolumn{3}{|l|}{ Educational level: } \\
\hline No formal education & 22 & 7.19 \\
\hline Primary education & 45 & 14.71 \\
\hline Secondary & 228 & 74.51 \\
\hline Tertiary & 11 & 3.59 \\
\hline
\end{tabular}

Table 3: Adverse Pregnancy Outcomes of Women who delivered at Intermediate Hospital Oshakati, Oshana Region, Namibia, July - September 2015

\begin{tabular}{lll}
\hline Characteristics & Frequency (n) & Percentage (\%) \\
\hline Maternal death & 6 & 1.96 \\
Neonatal death & 4 & 1.31 \\
Postpartum Haemorrhage & 20 & 6.54 \\
Puerperal sepsis & 1 & 0.33 \\
Eclampsia & 28 & 9.15 \\
Caesarean Section & 100 & 32.68 \\
Low birth weight & 66 & 21.57 \\
Fresh still birth & 5 & 1.63 \\
Macerated & 4 & 1.31 \\
None & 72 & 23.52 \\
Total & 306 & 100.00 \\
\hline
\end{tabular}

\subsection{Factors associated with adverse pregnancy out- comes}

In multivariate analysis, mothers living in a rural area were twice more likely to have an adverse pregnancy outcome compared to mothers living in an urban area (adjusted Odds Ratio [aOR] 2.00, 95\% CI: 1.08 to $3.69, \mathrm{p}=0.027$ ). We also found that mothers having shorter gestational period [32-37 weeks] were almost five times more likely to suffer an adverse pregnancy outcome compared to longer gestational period [38 -42 weeks] (aOR4.84, 95\% CI: 2.31 to $10.14, \mathrm{p}=0.0007)$. Our findings also indicate that mothers with lower levels of haemoglobin $(<10 \mathrm{gm} \%)$ were almost four times more likely to have an adverse pregnancy outcome $(\mathrm{aOR} 3.87,95 \% \mathrm{CI}: 1.79$ to $8.39, \mathrm{p}=0.001)$. Our results for body mass index (BMI) show that obese mothers [BMI $\geq 30$ $\mathrm{kg} / \mathrm{m}^{2}$ ] were almost five times more likely to have an adverse pregnancy outcome, compared to mothers having normal weight [BMI $18.5-24.9 \mathrm{~kg} / \mathrm{m}^{2}$ ] (aOR4.89, 95\% CI: 1.38 to 17.37 , $\mathrm{p}=0.014$ ). Finally, our results from the blood pressure measurements showed that mothers having moderately high blood pressure [Systolic/ Diastolic Blood Pressure (SBP/DBP): 150/100 $159 / 109 \mathrm{mmHg}$ ] were 15 times more likely to have an adverse pregnancy outcome compared to mothers having normal blood pressure [SBP/DBP $\leq 140 / 90 \mathrm{mmHg}$ ] (aOR15.15, 95\% CI: 1.78 to 128.68, $\mathrm{p}=0.013$ ). Age, region, employment status, marital status, education level, gravidity, parity and HIV status were not associated with having adverse pregnancy outcome (Table 2).

Table 2: Multivariate Analyses on Potential Risk Factors of Women who delivered t Intermediate Hospital Oshakati, Namibia, July - September 2015

\begin{tabular}{|c|c|c|c|c|c|c|c|c|}
\hline \multirow[t]{2}{*}{ Risk Factor } & \multicolumn{2}{|c|}{$\begin{array}{l}\text { Adverse Pregnancy Outcome, } \\
\mathrm{N}(\%)\end{array}$} & \multicolumn{3}{|c|}{ Univariate analysis } & \multicolumn{3}{|c|}{ Multivariate analysis } \\
\hline & No & Yes & OR & $95 \% \mathrm{CI}$ & $\mathrm{P}$ & $\mathrm{aOR}$ & $95 \% \mathrm{CI}$ & $\mathrm{P}$ \\
\hline \multicolumn{9}{|l|}{ Age, years } \\
\hline $12-19$ & $69(49.1)$ & $84(54.9)$ & 1 & & & & & \\
\hline $20-45$ & $73(47.7)$ & $80(52.3)$ & 0.90 & $0.57-1.41$ & 0.647 & & & \\
\hline \multicolumn{9}{|l|}{ Region } \\
\hline Kunene & $3(50.0)$ & $3(50.0)$ & 1 & & & & & \\
\hline Angola & $5(22.7)$ & $17(77.3)$ & 3.40 & $0.52-22.41$ & 0.203 & & & \\
\hline Ohangwena & $19(41.3)$ & $27(58.7)$ & 1.42 & $0.26-7.81$ & 0.686 & & & \\
\hline Omusati & $19(32.2)$ & $40(67.8)$ & 2.11 & $0.39-11.42$ & 0.388 & & & \\
\hline Oshana & $91(56.2)$ & $71(43.8)$ & 0.78 & $0.15-3.98$ & 0.153 & & & \\
\hline Oshikoto & $5(45.5)$ & $6(54.5)$ & 1.20 & $0.16-8.80$ & 0.164 & & & \\
\hline \multicolumn{9}{|l|}{ Employment } \\
\hline No & $124(46.4)$ & $143(53.6)$ & 1 & & & & & \\
\hline Yes & $18(46.2)$ & $21(53.9)$ & 1.01 & $0.52-1.98$ & 0.973 & & & \\
\hline \multicolumn{9}{|l|}{ Marital Status } \\
\hline Married & $9(45.0)$ & $11(55.0)$ & 1 & & & & & \\
\hline Single & $133(46.5)$ & $153(53.5)$ & 0.94 & $0.38-2.34$ & 0.896 & & & \\
\hline \multicolumn{9}{|l|}{ Education level } \\
\hline No formal education & $7(31.8)$ & $15(68.2)$ & 1 & & & & & \\
\hline Primary education & $15(33.3)$ & $30(66.7)$ & 0.93 & $0.31-2.78$ & 0.901 & & & \\
\hline Secondary education & $116(50.9)$ & $112(49.1)$ & 0.45 & $0.18-1.15$ & 0.094 & & & \\
\hline Tertiary education & $4(36.4)$ & $7(63.6)$ & 0.82 & $0.18-3.74$ & 0.794 & & & \\
\hline \multicolumn{9}{|l|}{ Residential area } \\
\hline Urban & $46(62.2)$ & $28(37.8)$ & 1 & & & 1 & & \\
\hline Rural & $96(41.4)$ & $136(58.6)$ & 2.33 & $1.36-3.98$ & 0.002 & 2.00 & $1.08-3.69$ & 0.027 \\
\hline \multicolumn{9}{|l|}{ Gestation, weeks } \\
\hline $38-42$ & $129(58.4)$ & $117(47.6)$ & 1 & & & 1 & & \\
\hline
\end{tabular}




\begin{tabular}{|c|c|c|c|c|c|c|c|c|}
\hline $32-37$ & $12(21.8)$ & $43(78.2)$ & 3.95 & $1.99-7.85$ & $<0.001$ & 4.84 & $2.31-10.14$ & 0.000 \\
\hline $26-31$ & $1(20.0)$ & $4(80.0)$ & 4.41 & $0.49-40.02$ & 0.187 & 4.71 & $0.46-48.46$ & 0.193 \\
\hline \multicolumn{9}{|l|}{ Haemoglobin } \\
\hline$>10 \mathrm{mg} \%$ & $131(50.0)$ & $131(50.0)$ & 1 & & & 1 & & \\
\hline$<10 \mathrm{mg} \%$ & $11(25.0)$ & $33(75.0)$ & 3.00 & $1.45-6.19$ & 0.003 & 3.87 & $1.79-8.39$ & 0.001 \\
\hline \multicolumn{9}{|l|}{ Body Mass Index } \\
\hline Normal & $92(42.0)$ & $117(56.0)$ & 1 & & & 1 & & \\
\hline Obese & $4(26.7)$ & $11(73.3)$ & 2.16 & $0.67-7.01$ & 0.199 & 4.89 & $1.38-17.37$ & 0.014 \\
\hline Overweight & $38(58.5)$ & $27(41.5)$ & 0.56 & $0.32-0.98$ & 0.043 & 0.84 & $0.45-1.58$ & 0.591 \\
\hline \multicolumn{9}{|l|}{ Blood Pressure } \\
\hline Normal & $136(51.5)$ & $128(48.5)$ & 1 & & & 1 & & \\
\hline Mildly high & $5(35.7)$ & $9(64.3)$ & 1.91 & $0.62-5.86$ & 0.256 & 2.28 & $0.69-7.52$ & 0.174 \\
\hline Moderately high & $1(10.0)$ & $9(90.0)$ & 9.56 & $1.19-76.55$ & 0.033 & 15.15 & $1.78-128.68$ & 0.013 \\
\hline Severely high & $0(0.0)$ & $18(100.0)$ & - & - & - & - & - & - \\
\hline \multicolumn{9}{|l|}{ Gravidity } \\
\hline $1-4$ & $132(46.2)$ & $154(53.8)$ & 1 & & & & & \\
\hline $5-9$ & $10(50.0)$ & $10(50.0)$ & 0.86 & $0.35-2.12$ & 0.739 & & & \\
\hline \multicolumn{9}{|l|}{ Parity } \\
\hline $0-4$ & $133(46.3)$ & 154 (53.7) & 1 & & & & & \\
\hline $5-9$ & $9(47.4)$ & $10(52.6)$ & 0.96 & $0.38-2.43$ & 0.931 & & & \\
\hline \multicolumn{9}{|l|}{ HIV status* } \\
\hline Negative & $116(46.4)$ & 134 (53.6) & 1 & & & & & \\
\hline Positive & $24(47.1)$ & $27(52.9)$ & 0.97 & $0.53-1.78$ & 0.931 & & & \\
\hline
\end{tabular}

$\mathrm{OR}=$ Odds Ratio, aOR=adjusted Odds Ratio, $\mathrm{CI}=$ Confidence Interval, $\mathrm{P}=\mathrm{P}$-value, $*$ - 5 unknown HIV status.

\section{Discussion}

We found that obesity in pregnant women was a risk factor associated with adverse pregnancy outcomes among women who delivered at IHO. The prevalence and impact of overweight and obesity in an Australian obstetric population found that the prevalence of maternal overweight and obesity was (43\%), which is higher than that reported in another study of Australian women giving birth in Queensland between 1998 and 2002, which reported that $34 \%$ of women were overweight or obese (Callaway, et al. (2006). Studies from South Africa and Sudan showed overweigh and obesity to be associated with increased likelihood of caesarean section, gestational diabetic mellitus (GDM), and macrosomia in pregnant women with obesity (Basu\&Jeketera, 2010). A study in China found an association between maternal weight and hypertensive disorders of pregnancy and GDM (Chen, et al. 2010).

We found that mothers with lower levels of haemoglobin $(<10$ gm\%) were almost four times more likely to have an adverse pregnancy. The low haemoglobin in pregnancy increases the risk of maternal and perinatal morbidity and mortality, and is associated with premature labor and low birth weight (Haider, et al.2013). According to the last two Uganda Demographic and Health Surveys, there was a decline in the prevalence of low haemoglobin in pregnancy in Uganda from $41.2 \%$ to $30.5 \%$ between 2001 and 2011 respectively (Uganda Bureau of Statistics II, 2012). We found that mothers having moderately high blood pressure. This could be due to poor socio-demographic characteristics e.g. unemployment, unmarried and lower educational status. Moderate high BP require antihypertensive treatment and there seems to be less risk of developing severe hypertension, but no difference in outcomes of preeclampsia, neonatal death, preterm birth, and small for gestational age babies with treatment (Abalos, et al. 2007). We also found that mothers having shorter gestational period [32-37 weeks] were almost five times more likely to suffer an adverse pregnancy outcome compared to longer gestational period [38 -42 weeks].

We found that pregnant women from rural areas were twice more likely to develop adverse pregnancy outcomes compared to women from urban areas. This could be due to poor access to information about pregnancy and its effects in rural areas whereas the information is readily available in urban areas in the form of internet, library, television and an adolescent friendly clinic. Therefore mothers from urban areas are likely to avoid an issue that predisposes them to adverse pregnancy outcomes.

We found that all maternal deaths occurred among mothers aged 20-45 years. This could be due to ignorance to seek medical care on time. Advanced maternal age ( $\geq 35$ years) is associated with increased stillbirths, preterm births, intrauterine growth restriction, and chromosomal abnormalities (Carolan, 2011 \&Ngowaet et, al. 2013). In some settings, older mothers have lower socioeconomic status, less schooling, and higher parity, whereas in others there are educated women who delay pregnancy for career reasons and are at increased risk of obesity, diabetes, hypertension, and associated pregnancy complications (Kenny et al.2013).

\section{Limitations}

We could not find the parents or guardians of some of the teenage mothers (minors) to give informed consent and we therefore excluded them from the study. Some patients' documents were also incomplete and unclear.

\section{Conclusions}

Living in a rural area, shorter gestational period, haemoglobin level $<10 \mathrm{gm} \%$, obesity, and having moderately high blood pressure were found to be significant risk factors for adverse pregnancy outcomes. All the maternal deaths were in the 20-45 years old pregnant mothers. We recommend educating women on these risk factors in order to reduce the burden of adverse pregnancy outcomes.

\section{Acknowledgement}

We would like to thank the Oshana regional Director Mr. Sakaria Taapopi for granting us permission to conduct this research work in the region and sincere gratitude to all participants who voluntarily participated in this study. We greatly appreciate the Centers of Disease Control and Prevention (CDC) Namibia and Ministry of Health and Social Services (MoHSS) for funding this study. Our sincere gratitude goes to the University of Namibia (UNAM) for approving this study and providing the ethical clearance certificate.

\section{References}

[1] Abalos E, Duley L, Steyn DW, Henderson-Smart DJ. Antihypertensive drug therapy for mild to moderate hypertension during pregnancy. Cochrane Database of Systematic Reviews. 2007. https://doi.org/10.1002/14651858.CD002252.pub2.

[2] Callaway, L. K., Prins, J. B., Chang, A. M., \& McIntyre, H. D. (2006). The Prevalence and Impact of overweight of overweight 
and obesity in an Australian obstetric population. Med J Aust, 5659.

[3] CDC. (2010). Advanced Management and Analysis of Data Using Epi Info for Windows. Zimbwabwe: CDC.

[4] Chen Z, Du J, Shao L, et al. Pre pregnancy body mass index, gestational weight gain, and pregnancy outcomes in China. Int J Gynaecol Obstet 2010; 109:41-44. https://doi.org/10.1016/j.ijgo.2009.10.015.

[5] Haider BA, Olofin I, Wang M, Spiegelman D, Ezzati M, Fawz WW. Anaemia, prenatal iron use, and risk of adverse pregnancy outcomes: systematic review and meta-analysis. BMJ. 2013; 346:f3443. https://doi.org/10.1136/bmj.f3443.

[6] https://www.winthrop.org/departments/institutes/family/ob-gyn (n.d.). Maternal-Fetal-Medicine/Adverse-Pregnancy-Outcomes. Maternal-Fetal-Medicine/Adverse-Pregnancy-Outcomes.

[7] JDK Ngowa, A Ngassam, JS Dohbit, C Nzedjom, JM Kasia Pregnancy outcome at advanced maternal age in a group of African women in two teaching hospitals in Yaounde, Cameroon Pan Afr Med J, 14 (2013) 134

[8] Latifah A. Rahman, Noran N. Hairi and NooriahSalleh. Association between Pregnancy Induced Hypertension and Low Birth Weight; A Population Based Case-Control Study. Asia Pac J Public Health. 2008; Basu JK, Jeketera CM, Basu D. Obesity and its outcomes among pregnant South African women. Int J GynaecolObstet 2010; 110:101-104.

[9] LC Kenny, T Lavender, R McNamee, SM O'Neill, T Mills, AS Khashan Advanced maternal age and adverse pregnancy outcome: evidence from a large contemporary cohort PLoS One, 8 (2013), p. e56583. https://doi.org/10.1371/journal.pone.0056583.

[10] M Carolan, D Frankowska Advanced maternal age and adverse perinatal outcome; a review of the evidence,Midwifery, 27 (2011), pp. 793-801. https://doi.org/10.1016/j.midw.2010.07.006

[11] Ministry of Health and Child Welfare Zimbabwe (2007). Maternal and Perinatal Mortality Study. Harare, Zimbabwe. P17-24.

[12] Ministry of Health and Social Services (2011). Namibia Demographic Health Survey 2006/2007. Windhoek,Namibia

[13] Ministry of Health and Social Services (2014). Annual report 2013/2014, Windhoek, Namibia

[14] Rayis DA, Abbaker AO, Salih Y, Adam I. Obesity and pregnancy outcome in Khartoum, Sudan. Int J GynaecolObstet 2011; 113:160161. https://doi.org/10.1016/j.ijgo.2010.12.008.

[15] Roberfroid D, Huybregts L, Lanou H, Henry MC, Meda N, Menten J, Kolsteren P. Effects of maternal multiple micronutrient supplementation on fetal growth: a double-blind randomized controlled trial in rural Burkina Faso. Am J Clin Nutr. 2008; 88(5):1330-1340.

[16] Tachiweyika Emmanuel, Gombe Notion, Shambira Gerald, ChadambukaAddmore, TshimamgaMufuta, ZizhouSimukai; Determinants of perinatal mortality in Marondera district, Mashonaland East Province of Zimbabwe, 2009.

[17] Uganda Bureau of Statistics II. Uganda Demographic and Health Survey 2011. Uganda: Kampala; 2012.

[18] UN.GeneralAssembly.Geneva: Human Rights Council, 2009 Preventable maternal Mortality and Morbidity and Human Rights.

[19] WHO. (2010). Nigeria national health report. Geneva: WHO.

[20] WHO (2012). Born too soon: the global report on preterm birth. Geneva: World Health Organisation. 